\title{
Final Progress Report for the NASA Inductrack Model Rocket Launcher at the Lawrence Livermore National Laboratory
}

\author{
L.S. Tung, R. F. Post, J.Martinez-Frias
}

June 27, 2001

Low

Livermore

National

Laboratory

U.S. Dapartment of Energy

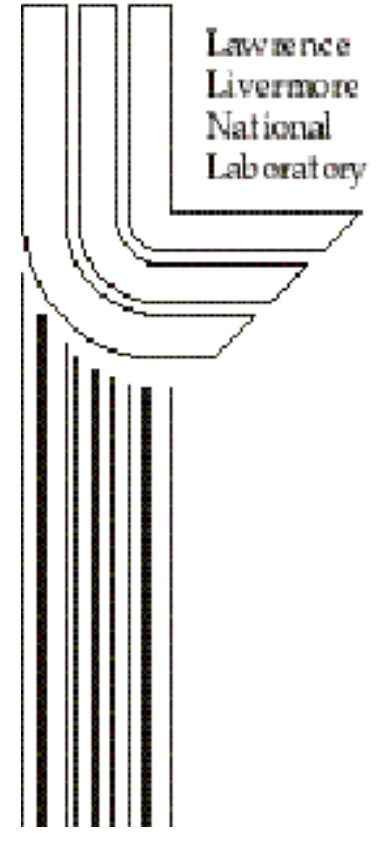




\section{DISCLAIMER}

This document was prepared as an account of work sponsored by an agency of the United States Government. Neither the United States Government nor the University of California nor any of their employees, makes any warranty, express or implied, or assumes any legal liability or responsibility for the accuracy, completeness, or usefulness of any information, apparatus, product, or process disclosed, or represents that its use would not infringe privately owned rights. Reference herein to any specific commercial product, process, or service by trade name, trademark, manufacturer, or otherwise, does not necessarily constitute or imply its endorsement, recommendation, or favoring by the United States Government or the University of California. The views and opinions of authors expressed herein do not necessarily state or reflect those of the United States Government or the University of California, and shall not be used for advertising or product endorsement purposes.

This work was performed under the auspices of the U. S. Department of Energy by the University of California, Lawrence Livermore National Laboratory under Contract No. W-7405-Eng-48.

This report has been reproduced directly from the best available copy.

Available electronically at http://www.doc.gov/bridge

Available for a processing fee to U.S. Department of Energy

And its contractors in paper from

U.S. Department of Energy

Office of Scientific and Technical Information

P.O. Box 62

Oak Ridge, TN 37831-0062

Telephone: (865) 576-8401

Facsimile: (865) 576-5728

E-mail: reports@adonis.osti.gov

Available for the sale to the public from

U.S. Department of Commerce

National Technical Information Service

5285 Port Royal Road

Springfield, VA 22161

Telephone: (800) 553-6847

Facsimile: (703) 605-6900

E-mail: orders@ntis.fedworld.gov

Online ordering: http://www.ntis.gov/ordering.htm

OR

Lawrence Livermore National Laboratory

Technical Information Department's Digital Library

http:/ / www.llnl.gov/tid/Library.html 


\title{
FINAL PROGRESS REPORT FOR THE NASA INDUCTRACK MODEL ROCKET LAUNCHER AT THE LAWRENCE LIVERMORE NATIONAL LABOR ATORY
}

\author{
L. S. Tung, R. F. Post, and J. Martinez-Frias \\ Lawrence Livermore National Laboratory, Livermore, California
}

\begin{abstract}
The Inductrack magnetic levitation system, developed at the Lawrence Livermore National Laboratory, was studied for its possible use for launching rockets. Under NASA sponsorship, a small model system was constructed at the Laboratory to pursue key technical aspects of this proposed application. The Inductrack is a passive magnetic levitation system employing special arrays of high-field permanent magnets (Halbach arrays) on the levitating cradle, moving above a "track" consisting of a close-packed array of shorted coils with which are interleaved with special drive coils. Halbach arrays produce a strong spatially periodic magnetic field on the front surface of the arrays, while canceling the field on their back surface. Relative motion between the Halbach arrays and the track coils induces currents in those coils. These currents levitate the cradle by interacting with the horizontal component of the magnetic field. Pulsed currents in the drive coils, synchronized with the motion of the carrier, interact with the vertical component of the magnetic field to provide acceleration forces. Motional stability, including resistance to both vertical and lateral aerodynamic forces, is provided by having Halbach arrays that interact with both the upper and the lower sides of the track coils.
\end{abstract}

At present, a 7.8 meter track composed of drive and levitation coils has been built and the electronic drive circuitry performs as designed. A $9 \mathrm{~kg}$ cradle that carries the Halbach array of permanent magnets has been built. A mechanical launcher is nearly complete which will provide an initial cradle velocity of $9 \mathrm{~m} / \mathrm{s}$ into the electronic drive section. We have found that the drag forces from the levitation coils were higher than in our original design. However, measurements of drag force at velocities less than $1 \mathrm{~m} / \mathrm{s}$ are exactly as predicted by theory. Provided here are recommended design changes to improve the track's performance so that a final velocity of $40 \mathrm{~m} / \mathrm{s}$ can be achieved with the existing track. This project was designed and built as part of a Phase II contract that started in Feb. 1999 and ended in Sep. 2000 at a cost of $\$ 600 \mathrm{~K}$. A detailed budget on how this funding was spent is also included here. 


\section{INTRODUCTION}

The Inductrack concept uses passive magnetic levitation that is generated when a moving object holding an array of permanent magnets moves over shorted loops of wire embedded in a stationary track (Ref. 1). The interaction of the magnetic field moving over the wires induces currents in the wire. Above a critical speed, the induced current interacts with the magnetic field to generate a repulsive force that levitates the object above the track. There are many potential applications of this concept that range from magnetic bearings in motors to levitating a cradle that carries a payload or a trainload of people. In particular, under NASA sponsorship at Lawrence Livermore National Laboratory, we have built a prototype to demonstrate the feasibility of this concept for initiating rocket launches.

The basic concept of passive magnetic levitation has already been demonstrated at LLNL (Ref. 2). In that experiment, a $20 \mathrm{~kg}$ cart was accelerated (at about $1 \mathrm{~g}$ ) to $12 \mathrm{~m} / \mathrm{s}$, a speed which was about 3 times greater than the critical speed needed for levitation. Following initial acceleration, the cradle entered the region of shorted coils, levitated, and coasted to a stop on its auxiliary wheels at the end of the 20 meter long track. Except for initial transients, which damped out in flight, the cradle behaved stably.

At this phase of the project, our goal was to demonstrate acceleration in excess of 10g's with stable levitation. (The high acceleration - higher than would be needed for magnetic launching - is dictated by our need to limit the track length and costs.) However, we have found that the levitation coils generated excessive drag, that we have characterized analytically and experimentally at low speeds, which caused the cradle to stop a few meters down the track. Nevertheless we suggest some simple design improvements based on the analysis described below that allow the cradle to reach a speed of $40 \mathrm{~m} / \mathrm{s}$ on the existing 7.8meter long track.

\section{LESSONS LEARNED}

Early in this phase of the project, a design flaw caused the levitation coils to generate higher drag force than expected. Consequently, at the end of this phase when the system was tested, the cradle stopped before reaching the end of the track. After investigation we discovered that an early design assumed the use of a levitation coil with a perimeter of $75 \mathrm{~cm}$. After several design changes, the final perimeter was $56 \mathrm{~cm}$ which was not updated in our models. Our model shows that the $75 \mathrm{~cm}$ coils result in a maximum drag force of $363 \mathrm{Nt}$ when the cradle travels at $13 \mathrm{~m} / \mathrm{s}$ whereas the $56 \mathrm{~cm}$ coils result in a peak drag of $486 \mathrm{Nt}$. In addition, as limited by safety conditions, the mechanical launcher (bungee cords in a protective, sliding cage) was limited to an initial cradle velocity of $9 \mathrm{~m} / \mathrm{s}$ and not $15 \mathrm{~m} / \mathrm{s}$ as had been previously assumed. Consequently not only was the drag force higher than expected but we were operating on positive slope side of the drag force curve (shown later).

We can overcome the increased drag with two approaches that will accelerate the cradle to $40 \mathrm{~m} / \mathrm{s}$ with the existing track length. Assuming that we use the existing mechanical launcher then we can increase the "launch velocity" by having sections of track that provide only electronic drive (about half the track). Hence, the initial velocity of the cradle will be beyond $13 \mathrm{~m} / \mathrm{s}$ when the levitation coils are reached. Second, doubling the number of resonant capacitors can boost the acceleration force. This increases the peak current and pulse width of the coils by a factor of 1.41 . With this improvement and changing replacing only 3 assemblies with drive only, the cradle can reach a speed of $40 \mathrm{~m} / \mathrm{s}$. These improvements can be done without changing the electronic bus work or the drive circuit design because the safe limits on the circuit components will not be exceeded. We have confidence in our drag force model because at low speeds (less than $3 \mathrm{~m} / \mathrm{s}$ ) the measured drag force agrees with our model. If all these improvements were implemented, the total cost would be approximately $\$ 20 \mathrm{~K}$. 


\section{THEORY}

\section{Levitation}

The Inductrack concept for passive magnetic levitation uses a special configuration of high strength permanent magnets. This configuration, called a Halbach array, has an array of permanent magnets with a direction of magnetization that is rotated by $90^{\circ}$ with respect to adjacent magnets (Ref. 3). Figure 1 shows the contours of constant magnetic flux around a 5-bar array that is similar to that used in the Inductrack experiment. Without the horizontally-polarized magnets, the flux would be equal on the top and bottom.

An infinite number of bar magnets in a Halbach configuration would produce a sinusoidal variation of field at a constant distance from the bottom of the array. For the five magnets, the field parallel to the bottom of the array $\left(B_{x}\right)$ and the field normal to the bottom of the array $\left(B_{y}\right)$ are nearly sinusoidal in the $x$ direction, parallel to the bottom of the array. Figure 2 shows these field profiles as generated using ANSYS (Ref. 4) for our array that is $1 \mathrm{~cm}$ thick, $13 \mathrm{~cm}$ (5 bars) wide, and $12 \mathrm{~cm}$ long. The remanent field of these magnets, composed of $\mathrm{NdFeB}$, is $1.23 \mathrm{~T}$. The field is $0.26 \mathrm{~T}$ at $1 \mathrm{~cm}$ from the array surface, which is the expected levitation height above the shorted coils.

The sinusoidal variation in $B_{x}(x)$ and $B_{y}(x)$ is critical to provide the proper time-variation in magnetic field experienced by the stationary wires as the magnets move by. As the field cuts through the nearest upper conductors in the track, the time-variation in magnetic field acts as a voltage source in each closed loop of wire. The effective circuit of this wire is just an inductor $L$ and resistor $R$ in series so that the levitation forces can be predicted through standard circuit theory. The excitation frequency $\omega$ of the circuit is $\omega=\mathrm{k} v$ where $k=2 \pi / \lambda, v$ is the array velocity $(\mathrm{m} / \mathrm{s})$, and $\lambda$ is the array wavelength $(0.1-\mathrm{m}$ as seen in Fig. 2). When $\omega \gg>R / L$ the phase of the current is shifted $90^{\circ}$ with respect to the voltage so that the current is in phase with the flux which maximizes the force in the $+y$ direction to provide lift and minimizes the drag force. For velocities substantially above than the transition speed of

$$
v_{t}=(\lambda R) /(2 \pi L)[\mathrm{m} / \mathrm{s}] \text {, }
$$

the cradle will lift off the track. For lesser velocities, the drag force, acting in the $-x$ direction, will decelerate the cradle. At a speed of $v_{t}$, the levitation and drag forces are equal.

The current $I_{L}$ induced in each closed loop is a function of the flux $\phi$ enclosed so that

$$
I_{L}=\phi / L=\lambda B_{0} /(2 \pi L) w \exp \left(-2 k y_{1}\right) \sin (k x)[\mathrm{A}]
$$

where $B_{0}$ is the theoretical surface field for an array of infinite area, $w=$ length of the excited wire and $y_{1}=$ gap between the array and wire. This surface field, as given by Halbach, is

$$
B_{0}=B_{r}(1-\exp (-k d)) \sin (\pi / M) /(\pi / M) \quad[\mathrm{T}]
$$

where $d=$ array thickness and $M=$ the number of magnets per wavelength ( 4 in the present case). The levitating force, averaged over $x$, is produced when the induced current is crossed with $\mathrm{B}_{\mathrm{x}}$ so that the average levitating force per closed loop is

$$
\left\langle F_{y}\right\rangle=\left\langle B_{x}(x) w I_{L}\right\rangle[\mathrm{N}] \text {. }
$$

The theory and assumptions behind Eq.s 1-4 can be found in other articles (Refs. 1, 2).

For velocities less than the critical speed, the drag force dominates. The drive coils must provide a force to exceed this drag force $F_{z}$ which can be expressed as 


$$
F_{z}=\frac{v B_{C}^{2} w^{2}}{2 R} \frac{N_{C}}{\left(\frac{k v L}{R}\right)^{2}+1}
$$

The field in the center of the coil wire is

$$
B_{C}=B_{0} \exp \left(-k\left(y_{1}-\Delta_{c} / 2\right)\right)[\mathrm{T}]
$$

where $y_{I}$ is the distance from the magnet surface to the wire and $\Delta_{\mathrm{c}}$ is the wire diameter. The inductance $L$ of the coil circuit is calculated to be [Ref. 2]

$$
L=\mu_{0} P_{c} / 2 k d_{c}[\mathrm{Hy}]
$$

where $P_{C}$ is the circuit perimeter [m] and $d_{C}$ is the effective spacing between wire centers of the coil. Finally $N_{C}$ is the number of circuits interacting with the cradle and is expressed as $N_{c}=\lambda n / d_{c}$ with $n=$ number of wavelengths.

\section{Acceleration}

Acceleration is provided to the cradle through the use of an impulsive current provided to drive coils that turn on when the peak of the $B_{y}$ field is present (refer to Fig. 2). Because the drive loop generates a local field that could affect the induced current in the nearby levitation coils, there is also a flux-canceling coil that is co-planar with the drive coil. The wire layout is configured so that the return path for current is far from the magnets yet creates a flux pattern that yields a zero net flux in the adjacent circuits.

The peak value of acceleration can be estimated from the peak strength of $B_{y}$ so that

$$
B_{y, \max }=B_{C} .
$$

Then the peak force $F_{p}$ from all the circuits, which is dependent on the drive current $\mathrm{I}_{\mathrm{D}}$, is given by

$$
F_{p}=N_{C} B_{y, \max } w I_{D} \quad[\mathrm{~N}] .
$$

The drive force is delivered in half sine-wave pulses with a pulse length of $\tau$ [sec]. Thus the velocity increase $\Delta v$ per pulse can be found from the momentum change so that

$$
\Delta v=1 / m F_{p} \int_{0}^{\tau} \sin \left(\frac{\pi t}{\tau}\right) d t=\tau F_{p} / \pi m .
$$

For our system, pulses are delivered every half-wavelength so that the pulse frequency $f_{p}$ is

$$
f_{p}=2 v / \lambda \quad[\mathrm{Hz}]
$$

and the average drive force $\mathrm{F}_{\text {drive }}$ is

$$
F_{\text {drive }}=m \Delta v f_{p} \quad[\mathrm{~N}] .
$$

\section{Eddy current deceleration}

An important element of the NASA model Inductrack system is the deceleration section at the end of the track needed to slow and safely stop the launch cradle. A similar system would be required in a full-scale Inductrack rocket launcher system. Theoretical analyses and preliminary design calculations have been made of a very simple, totally passive, system that meets the requirements of our model system. 
With our model cradle the targeted acceleration rates were expected to approach $10 \mathrm{~g}$ 's. Such high accelerations, although higher than those projected for a full-scale launcher, were needed in our case to reduce the length (and cost) of the track. For the same reason we needed to achieve as high, or even higher, deceleration rates following the acceleration. Thus the cradle was designed to withstand deceleration forces of order $40 \mathrm{~g}$, thereby substantially reducing the required total length of the track as compared to that required if the deceleration rate was limited to $10 \mathrm{~g}$.

There is, fortunately, a very simple way to accomplish this objective with minimal cost and complexity. A previously derived theory of the Inductrack includes a consideration of the levitating and drag forces that would arise if the close-packed circuits of the track were to be replaced by a sheet of conducting metal, stainless steel, for example. Although the levitating and centering forces would not be appreciably degraded, the drag forces would be greatly increased, owing to the high electrical resistivity of stainless steel. In this way multi-g deceleration rates can be achieved, in a highly controllable way, and without loss of levitation during the deceleration.

The theory shows that in the case at hand the drag force (arising from resistive losses associated with eddy currents induced in the conducting sheet) is proportional to the product of the area of the Halbach array and the electrical skin depth. Since the skin-depth depends on the frequency of excitation, thus upon the speed of the vehicle, the relationship between drag force and speed (above a low critical speed) can be expressed by an equation of the form

$$
F_{\text {drag }}=K v_{0}^{1 / 2}[\mathrm{~N}]
$$

where the parameter $\mathrm{K}$, varying with the square root of the resistivity of the conducting sheet, is in addition proportional to the product of the area of the Halbach arrays and an exponentially decreasing term dependent on the separation gap between the surface of the Halbach arrays and the surface of the conducting sheet. The resistivity of stainless steel (or that of ordinary yellow brass) is high enough to yield $\mathrm{K}$ values that can produce the desired deceleration rates. With the above dependence on velocity of the drag force, an equation can be derived giving the stopping distance, $\mathrm{S}$, for the cradle. This equation is

$$
S=\frac{2}{5} \frac{M}{K} v_{0}^{5 / 2}[\mathrm{~N}]
$$

where $\mathrm{M}[\mathrm{kg}]$ is the cradle mass and $v_{0}[\mathrm{~m} / \mathrm{s}]$ is its velocity at the starting point of the deceleration section.

As an example, if stainless steel sheets are used in the deceleration section, spaced with a gap of $0.7 \mathrm{~cm}$ from the surface of the Halbach arrays, an initial deceleration rate of $40 \mathrm{~g}$ is predicted. If the cradle velocity after acceleration is 100 meters/sec this leads to a stopping distance of approximately 10 meters.

\section{Experiment}

\section{Mechanical}

\section{Overview}

In the present phase of development, the Inductrack test track is 22.8 meters long. Mechanical acceleration, provided by bungee cords in a safe sliding cage that is 5 meters long, will be used to launch the cradle. This provides acceleration to $8.9 \mathrm{~m} / \mathrm{s}$ when the electrical drive and levitation section is reached. Mechanical acceleration is considerably less expensive than electrical drive at low velocities. The next 7.8 meters is the acceleration/levitation section of track. Here the drive coils are interleaved with the levitation 
coils every $5 \mathrm{~cm}$. The drive coils are $1 \mathrm{~cm}$ wide and the levitation coils are $4 \mathrm{~cm}$ wide. The remaining track length of 10 meters has a non-magnetic stainless steel sheet that provides deceleration caused by the eddy currents in the conducting sheet as described earlier.

\section{Cradle}

The cradle, pictured in Fig. 3, is composed of carbon-fiber composite material and has a length of $65 \mathrm{~cm}$. A 3d ANSYS (Ref. 4) computer simulation aided in the development of this design. The analysis was used to minimize the weight yet withstand $40 \mathrm{~g}$ 's of acceleration or deceleration. It was also used to design the structure necessary to keep the cradle from "opening" due to the repulsion of the magnets away from the track and to calculate the natural frequencies of the cradle structure. The cradle has arms that extend past the track and surround the guide rails. As seen in the sketch of the end view in Fig. 4 and in the photo of the cradle on the track in Fig. 5, the C-guides on these arms are needed to prevent the track from touching the magnets prior to levitation. The magnets are housed in an aluminum box on the inside of the cradle. The cradle without the magnets weighs $3 \mathrm{~kg}$ and with the magnets weighs $9.3 \mathrm{~kg}$.

There are three arrays of magnets on the front and three on the back of the cradle. These magnets are located next to the track inside the cradle ribs as pointed out in Figs. 3 and 4. The lower magnets oppose the force in the upper magnets. The upper magnets have a width of $12 \mathrm{~cm}$ and the lower a width of $8 \mathrm{~cm}$.

Because the lower magnets are at a $45^{\circ}$ angle to the upper magnets, only $6 \%$ of the repulsive force from the top magnets balances the weight of the cradle and magnets. The remainder is used to center the cradle about the track to provide stability. The total weight of the cradle and magnets is $9.3 \mathrm{~kg}$.

\section{Launcher}

The mechanical launcher, pictured in Fig. 6, is composed of an aluminum cage with 6 bungee cords inside. The force characteristics of the 6 bungee cords was determined by measuring the length as a function of a static weight hung on the cords. A plot is shown in Fig. 7 and a numerical fit was applied to the data. A fixed spring constant is not used in the energy balance because we operate in the non-linear part of the force curve in order to maximize the launch velocity. The launch velocity $v_{L}$ is found by integrating the force over the distance between extension and release (or cradle launch point) so that

$$
v_{L}=\left(\frac{2}{M_{L}} \int_{y r e l}^{\text {yext }} F(y) d y\right)^{1 / 2}[\mathrm{~m} / \mathrm{s}]
$$

The extended yext and released yrel lengths are relative to the free length of $1.8 \mathrm{~m}$. The weight of the launcher plus the cradle is $M_{L}=15 \mathrm{~kg}$. Thus the maximum launch velocity that we felt was still safe and which required a reasonable force to cock the launcher was $v_{L}=8.9 \mathrm{~m} / \mathrm{s}$. Eight cords were not chosen because of the tight space within the sliding cage and of the greater force to cock the launcher. 


\section{Electro-magnetic}

\section{Experimental setup}

The following table summarizes the parameters of our experimental setup.

\begin{tabular}{|l|l|}
\hline Calculated launch velocity $=8.94 \mathrm{~m} / \mathrm{s}$ & Cradle mass $=9.33 \mathrm{~kg}$ \\
\hline $\begin{array}{l}\mathrm{B}_{\mathrm{t}}=\mathbf{0 . 2 5 5} \mathrm{T} \text { (at } \mathrm{y}_{\mathbf{1}}=\mathbf{1} \mathrm{cm} \text { from magnet array } \\
\text { surface which is at the levitation coil acc. to } \\
\text { ANSYS calculations) }\end{array}$ & Wavelength $\lambda=0.1 \mathrm{~m}$ \\
\hline Wavelengths per cradle $=2$ & Levitation wire diameter $\Delta_{\mathbf{c}}=\mathbf{0 . 1 1}$ inches \\
\hline 13 turns in $0.04 \mathrm{~m}$ of levitation coil & Levitation coil perimeter $\mathbf{P}_{\mathbf{c}}=\mathbf{0 . 5 6} \mathbf{~ m}$ \\
\hline $0.83 \Omega$ per $1000 \mathrm{ft}$ of $\# 10$ levitation wire & Drive current $=7000 \mathrm{~A}$ \\
\hline $\begin{array}{l}\text { Pulse width of drive current }=600 \mu \mathrm{sec} \\
\text { Drag force multiplier }=0.8(80 \% \text { of space } \\
\text { occupied by levitation and } 20 \% \text { by drive coils) }\end{array}$ & $\begin{array}{l}\text { Length of interleaved drive } \& \text { levitation section } \\
=7.8 \text { m }\end{array}$ \\
\hline
\end{tabular}

Table I. Summary of experimental parameters.

Within each set of levitation coils, which are $4 \mathrm{~cm}$ wide, are close-packed loops of \#10 wire. These are shown in Fig. 5 as wrapped around a wooden hexagonal core. The perimeter of each loop is $56 \mathrm{~cm}$. Each loop has a resistance of $1.5 \times 10^{-3} \Omega$ and inductance of $1.8 \times 10^{-6} \mathrm{H}$ according to Eq. 7. Applying these values to Eq.1, one finds the transition speed for our levitation coils is $13.3 \mathrm{~m} / \mathrm{s}$. In the experiment, levitation will be confirmed by inspection with a high speed camera.

The NdFeB magnets with a $B_{r}=1.2 \mathrm{~T}$ have a thickness $\mathrm{d}$ of $1 \mathrm{~cm}$ and $M=4$ magnets per wavelength (as seen in Fig. 2). According to Eq. 3 then the field at the surface (if the array were infinitely long) would be $B_{0}=0.52 \mathrm{~T}$. We anticipate that the cradle will levitate at $\mathrm{y}_{1}=1 \mathrm{~cm}$ above the track. We also assume that the lateral arrays will levitate at $1 \mathrm{~cm}$ above the track. Thus, using Eq. 2, one finds that the current generated in each loop by the presence of the three, moving Halbach arrays, that have a total length of $w=12+2 * 8 \mathrm{~cm}$, is $570 \mathrm{~A}$. With Eq. 4, one finds that the total repulsive force provided by just the top array is $1450 \mathrm{~N}$. With $94 \%$ of this force contributing to stability, the remaining lifting force provided by all six arrays is $166 \mathrm{~N}$. This should provide sufficient lift with some operating margin for the $9.3 \mathrm{~kg}$ cradle assembly.

The drive coils are separated by $5 \mathrm{~cm}$ to align with the peaks in $B_{y}(x)$ seen in Fig. 2. The location of the drive coils is seen in Fig. 5 as the vertical lines between the levitation coil blocks. Note that because $B_{y}(x)$ changes sign, the current pulse must also switch directions to still produce a forward force. Thus six drive coils (3 front and 3 back) are energized simultaneously to provide acceleration. A pulse of $7000 \mathrm{~A}$ with a fixed width of 600 micro-seconds is provides the acceleration in the driven section of the track. Using only Eqs. $10-12$ as if there were no drag from the levitation coils, one can calculate that the cradle can achieve $30 \mathrm{~m} / \mathrm{s}$ in 7.8 meters of drive coils. Although a variable pulse width could provide optimal acceleration in a 
shorter distance, this option is very expensive because of the number of high current switches required.

The drive coils themselves comprise a single turn of \# 6 square insulated magnet wire. A sketch of a drive coil is shown in Fig. 8. During the current pulse, we were concerned with the generation of magnetic flux within the space inside each drive coil that would interfere with adjacent levitation coils. Hence the compensation coils were designed to provide a return path for the current so that the flux was canceled. A compensation coil and how it overlays with a drive coil are shown in Fig. 8.

The drive circuitry is composed of triggered pairs of photo diode detectors and emitters mounted along the track as shown in Fig. 5 and in detail in Fig. 9. When the infrared light is blocked by the comb (seen in Fig. 9 attached to the cradle between the C-guides) the drive pulse is initiated. The sensors and comb are located so that the drive coils are pulsed when centered under the 6 locations of peak vertical magnetic field. As the cradle straddles two assemblies, all 26 drive coils are triggered to ensure continuous acceleration between sections although only 6 of the energized drive coils are actually needed for the acceleration. This was done to simplify the design and save costs.

A series invertor is used as an ac switch for each group of drive coils. When triggered, the series invertor both energizes the desired group of coils and creates the half-sine wave pulse of $7000 \mathrm{~A}$ that is $600 \mu \mathrm{sec}$ wide. This pulse width and amplitude depend on the inductance and resistance of the coils, the capacitance of the resonant capacitor, and the dc bus voltage. The pulse width could have been varied in discrete intervals along the track by changing the value of the resonant capacitors but the cost of this design was prohibitive. Typical boxes that contain the resonant capacitors and thyristor switches are shown in Figs. 10 and 11. The power supply is shown in Fig. 12.

To measure velocity, a coil is placed around a current lead coming from one of the resonant capacitor banks. The changing current is picked up by the coil and monitored on a scope. The rate that pulses are detected on the pick-up coil indicate the rate that the capacitors are fired. Since the teeth in the sensor blocker comb and the sensors are separated by a fixed distances along the track, the measured pulse rate is a measure of cradle velocity.

\section{Drag force predictions and measurement}

The levitation coils also have a drag force that is described by Eq. 5. The drag force peaks at $486 \mathrm{~N}$ around $13 \mathrm{~m} / \mathrm{s}$. Consequently the launch velocity should be greater than this or else increased velocity increases the drag. As we have predicted and observed, the cradle stops in less than a meter down the track even with the drive coils activated. A plot of the drag force as based on Eq. 5 is shown in Fig. 13.

Experimental data was taken for velocities less than $1 \mathrm{~m} / \mathrm{s}$. We measured the velocity of a person pulling the cradle while using a calibrated fish scale to measure the drag force. This data is shown in Fig. 14 with the same theory of Eq. 5 but at low velocities. The data shows good agreement even with our crude measuring system.

\section{Velocity predictions and measurement}

Using Eqs. 5 and 12 for the drag and drive forces, one can predict the velocity profile and stopping distances (for low launch velocities). Table II shows the prediction of stopping distances for velocities typical of a hand launch or a mechanical launch. With the existing system, the drag force exceeds the drive force and the cradle stops in less than a meter. Even with the mechanical launcher, the cradle is predicted to travel only 3 meters. Note that the analysis assumes that all of the drag force and drive forces are at one location rather than spread over $60 \mathrm{~cm}$. We observed that typical hand launches resulted in the cradle stopping less than a meter down the track with the full $7000 \mathrm{~A}$ of drive current. This initial observation 
prompted the investigation into the reason for the large drag force.

\begin{tabular}{|c|c|}
\hline Launch velocity $[\mathbf{m} / \mathbf{s}]$ & Stopping distance $[\mathbf{m}]$ \\
\hline 1 & 0.28 \\
\hline 2 & 0.57 \\
\hline 3 & 0.87 \\
\hline 8.9 & 3.36 \\
\hline
\end{tabular}

Table II. Prediction of stopping distances with 7000 A of drive current for various launch velocities.

\section{SUGGESTED IMPROVEMENTS}

\section{Drive only sections}

The presence of the levitation coils causes a drag force at low velocities. Consequently one improvement is to replace some of the front-end assemblies of levitation/drive with drive only. The choice of how many assemblies to replace depends on the location of the cradle when the peak drag force is exceeded with drive only. Obviously the more assemblies that are replaced the greater the final velocity but less of a length during levitation is available for observation. Ideally a new section of drive only could be added between the mechanical launcher and the levitation/drive section. However this would require considerably more labor and costs to rebuild part of the track and run additional bus work. Just replacing the drive/levitation assemblies with drive only is the simplest, most cost-effective fix. A drive-only assembly would be very simple because a compensation coil would not be needed. Thus 13 single-turn drive coils could be wound on a solid wooden block $65 \mathrm{~cm}$ long. This assembly would not require the special fabrication techniques needed for the levitation/drive assemblies.

To decide on which sections to replace, one must calculate the velocity profile with different lengths of both types of assemblies. The final velocity in the drive only section is then used as the new "launch velocity" in the shortened levitation/drive section. The lengths are in units of $65 \mathrm{~cm}$ assemblies so that the new sections can just replace the old. Figure 15 shows the various options for our 7.8 meter track assuming a constant mechanical launch velocity of $8.9 \mathrm{~m} / \mathrm{s}$. For pure drive, the cradle can reach $30 \mathrm{~m} / \mathrm{s}$ but then no levitation would be observed. At the other extreme, with even two assemblies replaced, the cradle stops before the end of the track. The optimum so that levitation could still be observed would be to replace 5 assemblies so that levitation would be observed over a length of 4.5 meters.

\section{Double the capacitance}

A second choice that can also be combined with the above option is to double the number of resonant capacitors. The resonant capacitors banks are relatively small in size and doubling their size would not be a difficult or expensive task. In this way the pulse width and height increases by the square root of two to 848 $\mu \mathrm{sec}$ and $9899 \mathrm{~A}$. The existing circuitry can also safely handle the additional current. We also analyzed the various assembly options with this pulse width and height and displayed the result in Fig. 15 . With the existing configuration of 12 levitation/drive assemblies ( 0 for drive only) then $32 \mathrm{~m} / \mathrm{s}$ can be attained and levitation should be observed over the whole 7.8 meters. An even greater improvement can be made by replacing some sections with drive only. As seen in Fig.15, the optimum would be to replace about 2 assemblies then $42 \mathrm{~m} / \mathrm{s}$ can be reached and levitation would be observed over 6.5 meters. 


\section{PROJECT EXPENDITURES}

Project expenditures for Phase II which covered expenses from Feb. 1999- Sep. 2000 are summarized in App. I. The total amount charged to NASA was $\$ 560 \mathrm{~K}$. This amount includes the additional extension provided by NASA in Feb. 2000. Most of the Inductrack was built between April and September of 2000.

A considerable amount of effort was put forth in volunteered time by all of the team members. In addition, much equipment was borrowed from other LLNL programs or found in salvage. So for future efforts on estimating costs, we calculated that the total value of the effort was $\$ 875.6 \mathrm{~K}$; of this $76 \%$ was labor costs. The majority of material costs went toward the drive circuitry. The additional voluntary efforts and equipment need to be included in the total costs funded for future improvements of the Inductrack experiment.

\section{FUTURE}

In the near future, for additional funds of $\$ 20 \mathrm{~K}$, we can improve the track so that the cradle can achieve 30 to $40 \mathrm{~m} / \mathrm{s}$ given a launch velocity of $9 \mathrm{~m} / \mathrm{s}$. This cost would cover two weeks of labor and materials to replace two assemblies with drive only and double the number of resonant capacitors. A cost breakdown for this effort follows:
Engineer
100 hours
Mechanical Technician
40 hours
Senior Scientist
12 hours

$\begin{array}{ll}\text { Wages } & \$ 6668 \\ \text { Materials } & \$ 4280 \\ \text { Facility Chg } & \$ 582 \\ \text { Indirect Costs } & \$ 8470\end{array}$

Total $=\$ 20 \mathrm{~K}$

It is LLNL's recommendation that in the long term, diagnostics that analyze the stability of the cradle during levitation should be added. 


\section{ACKNOWLEDGMENTS}

Contributions from William Kent-Lead technician, Don Podesta—volunteer technician, Dan ShimerElectrical engineer, Ernie Schwarz-Electrical designer and scrounger, Nick Patz-Graduate student analyst and cradle builder, and Brian Smith-Summer student technician are gratefully acknowledged. A special appreciation is extended to YLA of Benicia, CA who donated the materials and equipment needed to build the cradle. This work was being funded under NASA contract number \# H27814D.

\section{REFERENCES}

1. R. F. Post, "Magnetic Levitation for Moving Objects," U.S. Patent No. 5,722,326.

2. Accepted for publication in the IEEE Transactions on Applied Superconductivity (Proc. of the $16^{\text {th }}$ International Conf. on Magnetic Technology, Sept. 1999).

3. K. Halbach, "Application of permanent magnets in accelerators and electron storage rings," Journal of Applied Physics, vol. 57, p.3605, 1985.

4. ANSYS User's Manual Revision 5.5, Vol. 1, Procedures, Swanson Analysis Systems, Inc. 1998. 


\section{Appendix I: Expenditures}

\section{Phase II (Feb 1999 -Dec. 2000) Labor+Procurement Value $=\$ 875.6 \mathrm{~K}$ \\ (Total Phase II Charged $=\$ 560 K)$}

\section{Phase II Procurement Value $=\$ 208.6 K$}

magnets $=10.5 \mathrm{~K}$

(of which $30 \%$ was donated)

track $=24.1 \mathrm{~K}$

drive/lev circuitry+coils + sensors $=154.9 \mathrm{~K}$

(For 7.8 meters of acceleration but some components such as power supply and capacitors do not scale with length.)

cradle $=17 \mathrm{~K}$

eddy current break $=0.6 \mathrm{~K}$

launcher $=1.5 \mathrm{~K}$

\section{Phase II Labor Value $=\$ 667 \mathrm{~K}$}

Labor Total $=36.4$ months $($ donated $=38 \%)$

Total Charged $=22.6$ months $=\$ 414 \mathrm{~K}$

Engineering $=8.84 \mathrm{mo}$

Safety notes $=$

cradle/mag design $=$

$3 d$

Drive/lev coil design=

$87 \mathrm{~d}$

Final system test $=$

$64.5 \mathrm{~d}$

launcher design=

$2 \mathrm{~d}$

design sensor=

$16 d$

20d

Technician $=16.5 \mathrm{mo}$

Install drive circuitry=

old capacitors refurbished $=$

track support - design $=$

track support- install, = 
cradle/mag design=

build cradle (inc magnets) $=$

eddy current break design/build

vendor visits/procurement

safety inspections

build launcher

Final system test

\section{Coordinator $($ launcher $)=3.0 \mathrm{mo}$}

Launcher vendor visits

$0.1 \mathrm{~d}$

Procure drive/lev: circuitry and track coils

coil ve ndor visits $=$

Drafting \& layout $=3.7 \mathrm{mo}$

drive comp (boxes, trigger, busbar) layout

$60 \mathrm{~d}$

launcher drawings drafted

$5 d$

coil drawings drafted $=$

Presentations $=0.3 \mathrm{mo}$

travel\& talk $=$

NASA visit $=$

\section{Project management $=4.1 \mathrm{mo}$}

Weekly

Safety procedures

Scope change

Final report \& budget analysis
$117 \mathrm{~d}$

$31.9 \mathrm{~d}$

$6 d$

19d

$1 d$

$5 d$

$3 d$ 


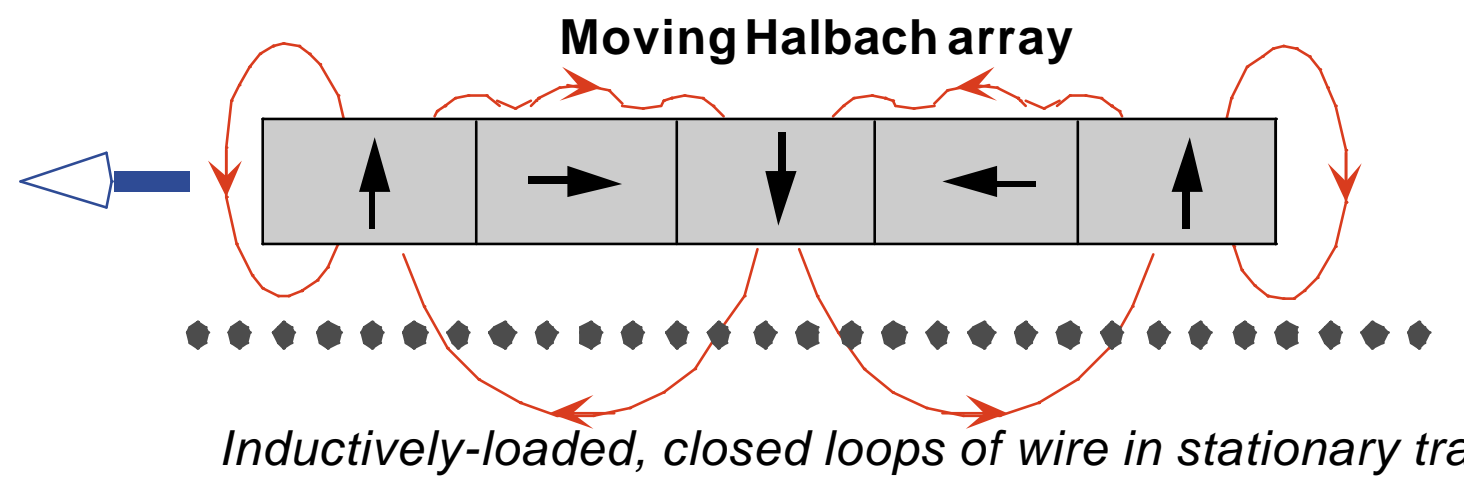

Figure 1. Sketch of passive magnetic levitation using a Halbach array of magnets. The horizontallypolarized magnets concentrate the flux on one side of the array and help to form the sinusoidal flux shape.

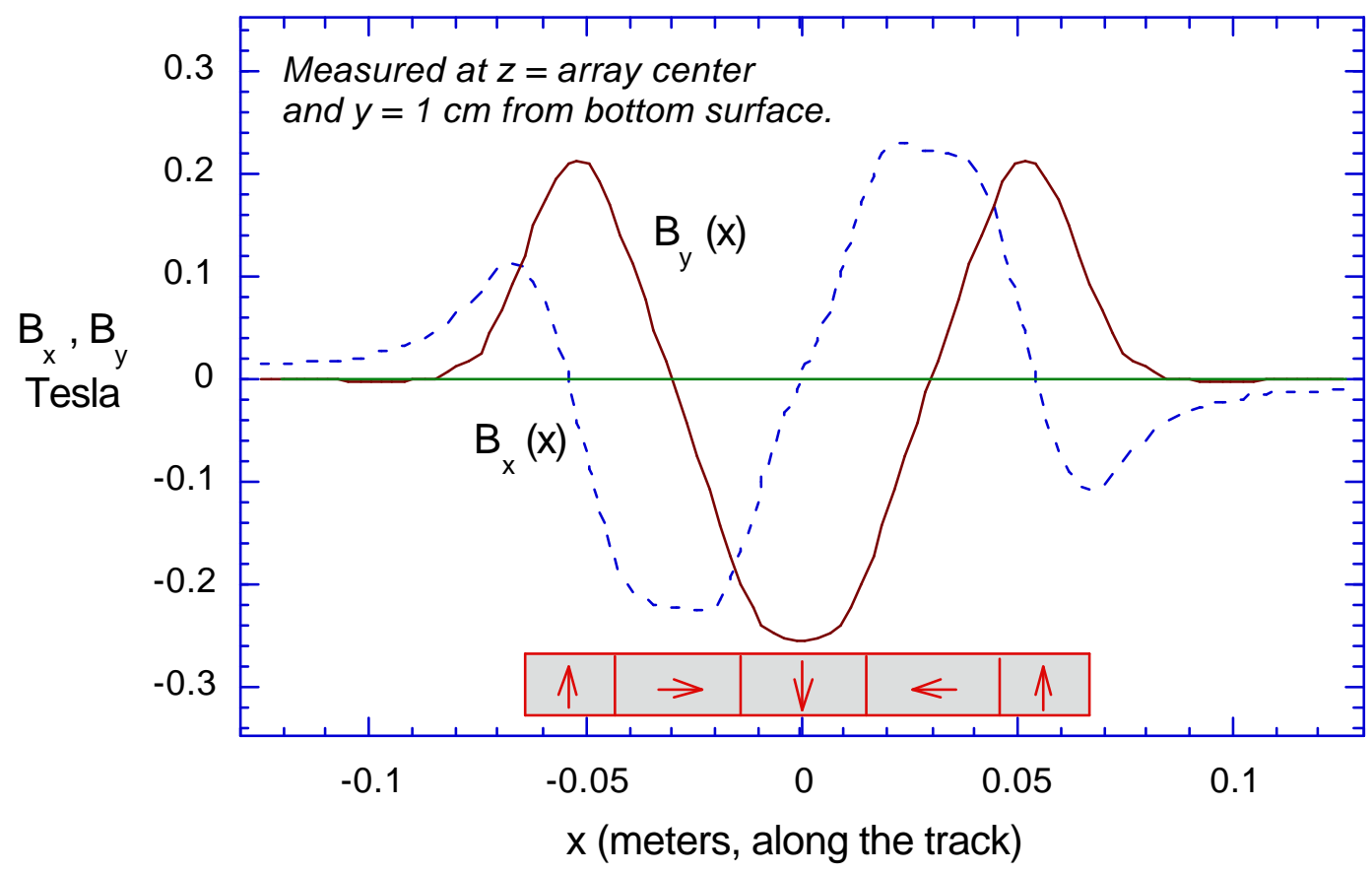

Figure 2. Variation of $B_{x}$ and $B_{y}$ along the track (in $x$ ) indicating the nearly sinusoidal behavior. Results are calculated from a 3d model of the Halbach array using ANSYS. 


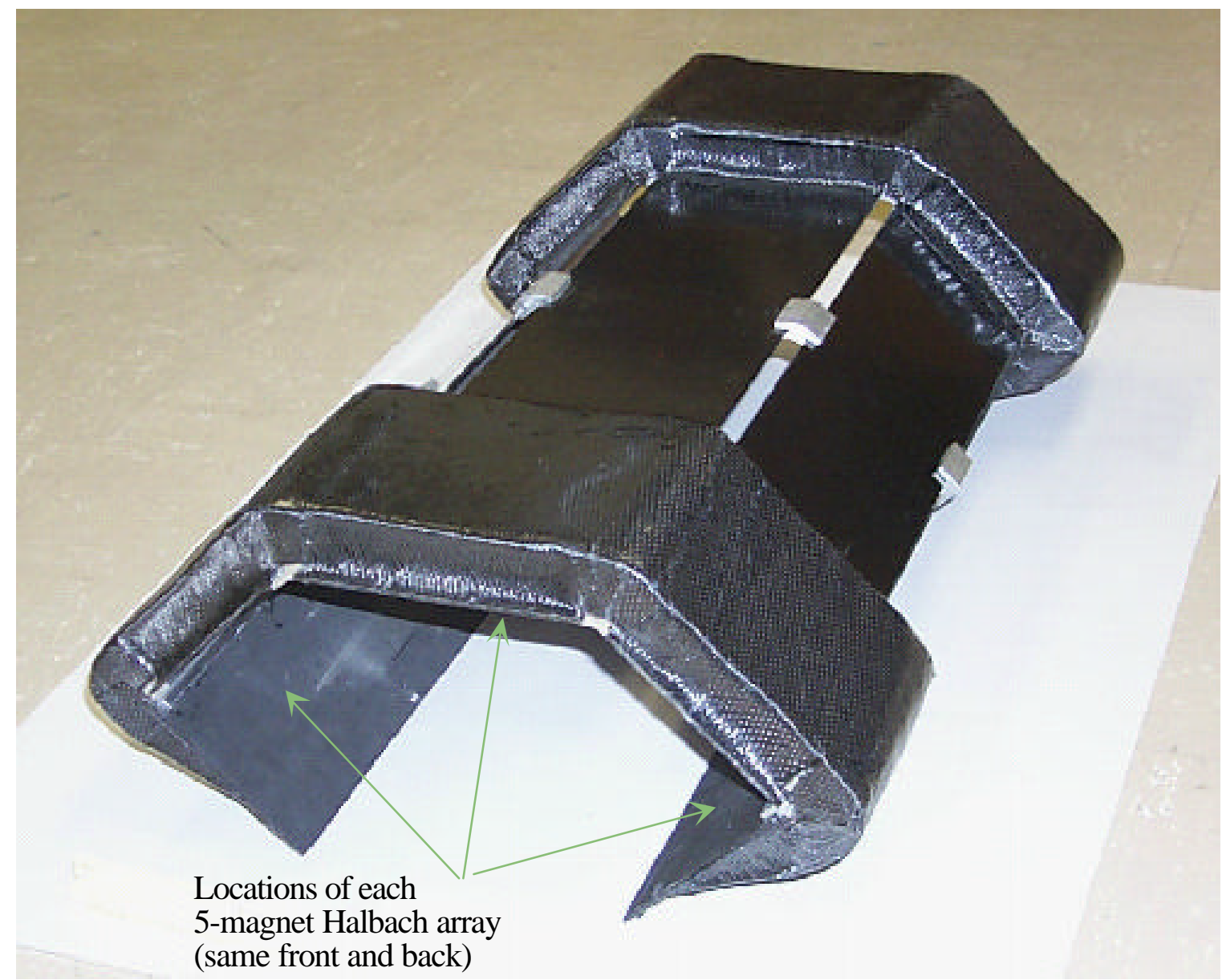

Figure 3. Photo of carbon fiber cradle (magnets not shown). The length is $65 \mathrm{~cm}$. 


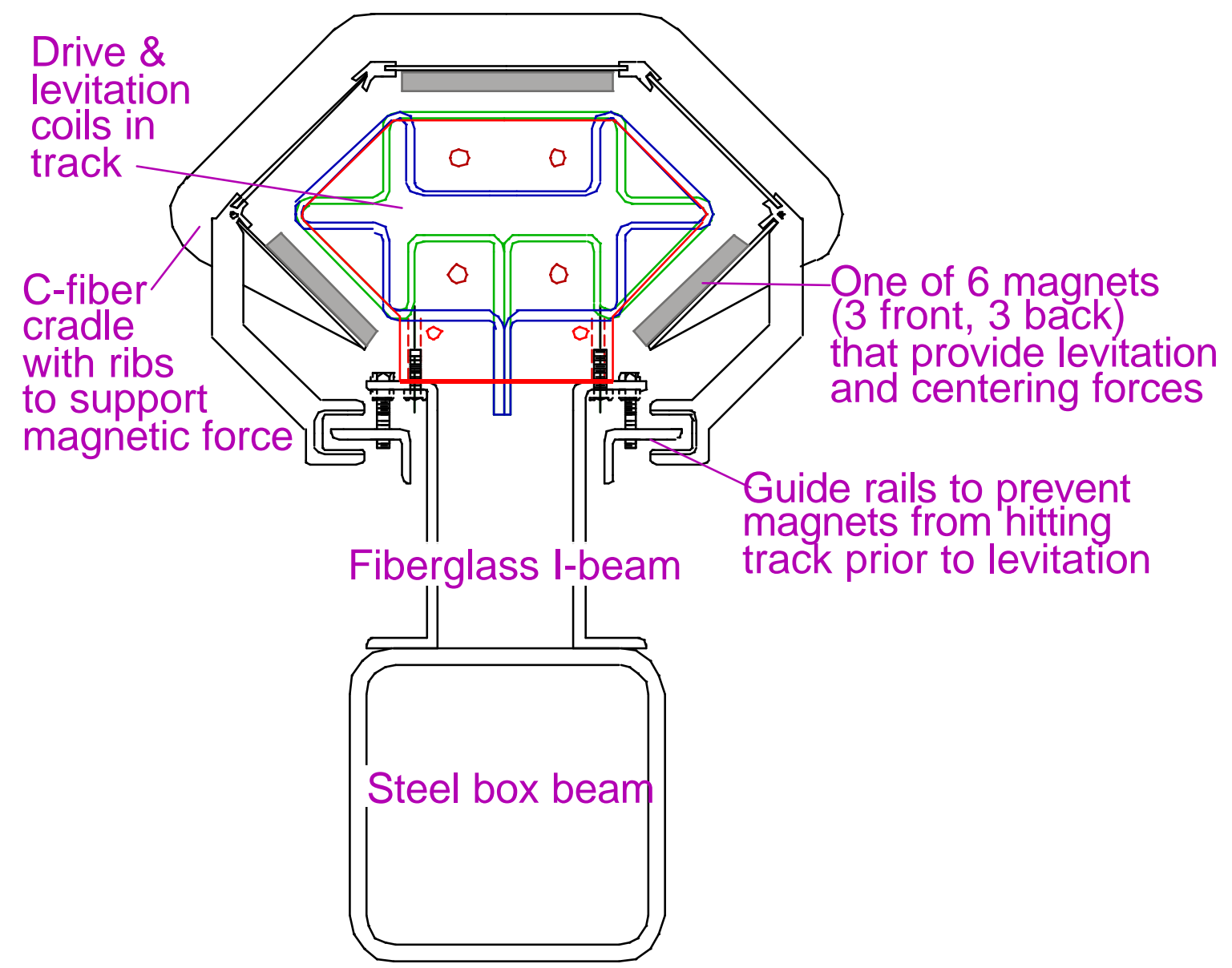

Figure 4. End view of cradle wrapped around track assembly. 


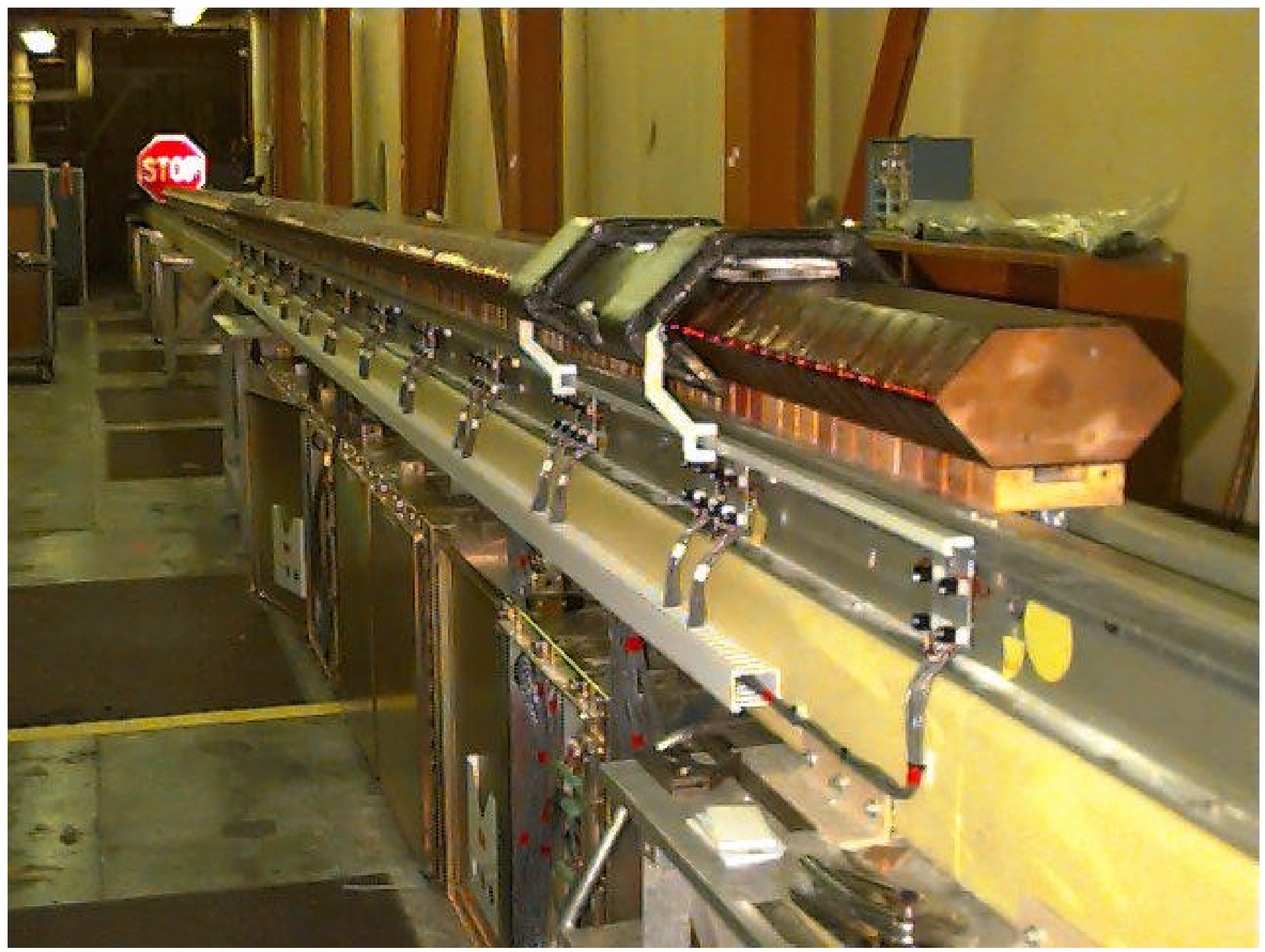

Figure 5. Actual track with cradle on guide rails. As shown, the cradle is sitting over the $2^{\text {nd }}$ of 13 assemblies of drive and levitation coils. The $\mathrm{C}$-guides are wrapped around the rails. The photo diode emitter and sensor pairs are located every $65-\mathrm{cm}$ along the track. Under the track are the boxes containing the resonant and filter capacitors and thyristor switches. In the last $10-\mathrm{m}$ before the stop sign is the passive deceleration section. 


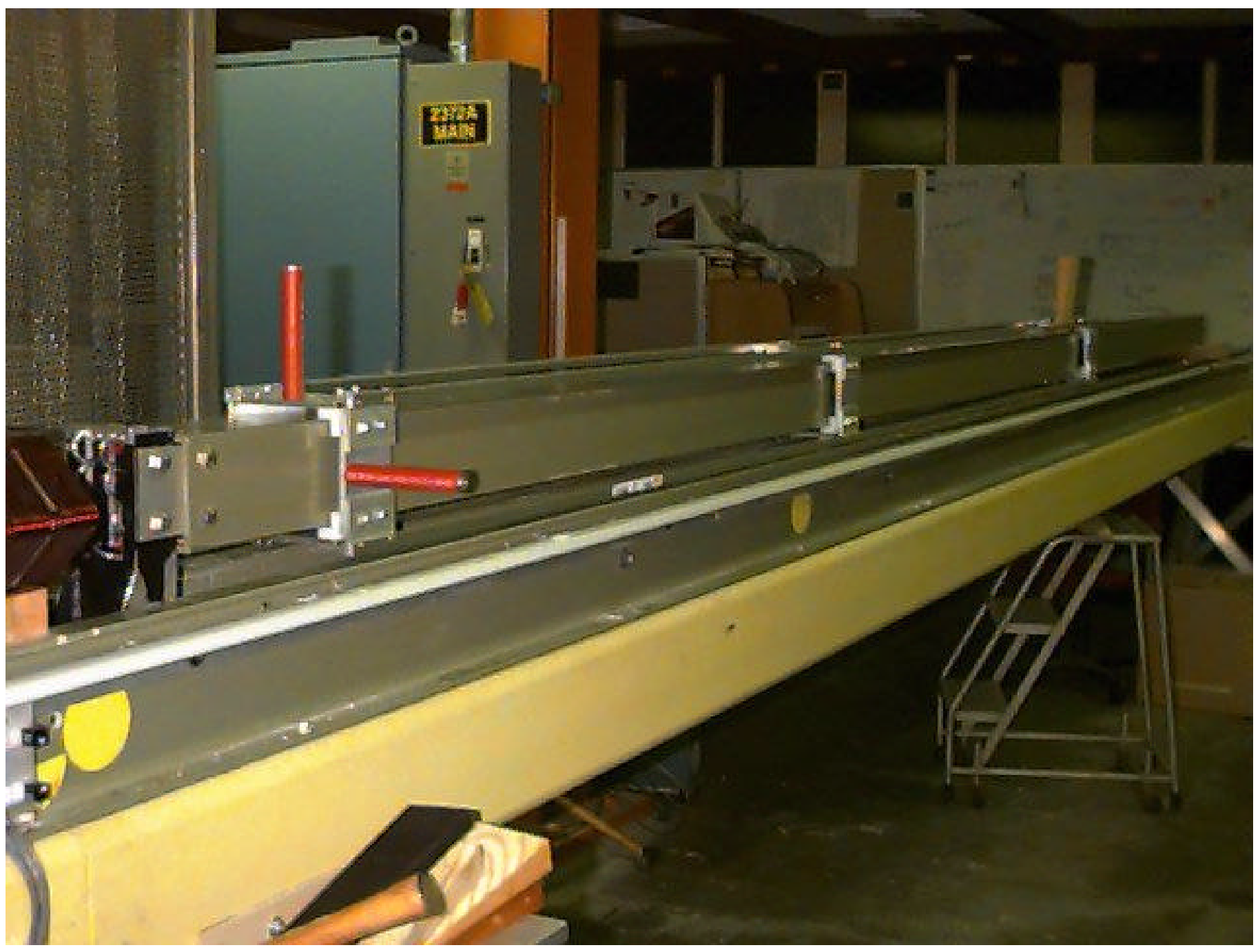

Figure 6. Mechanical launcher composed of a sliding cage with 6 bungee cords inside. The red handles are used to pull back the launcher manually. 


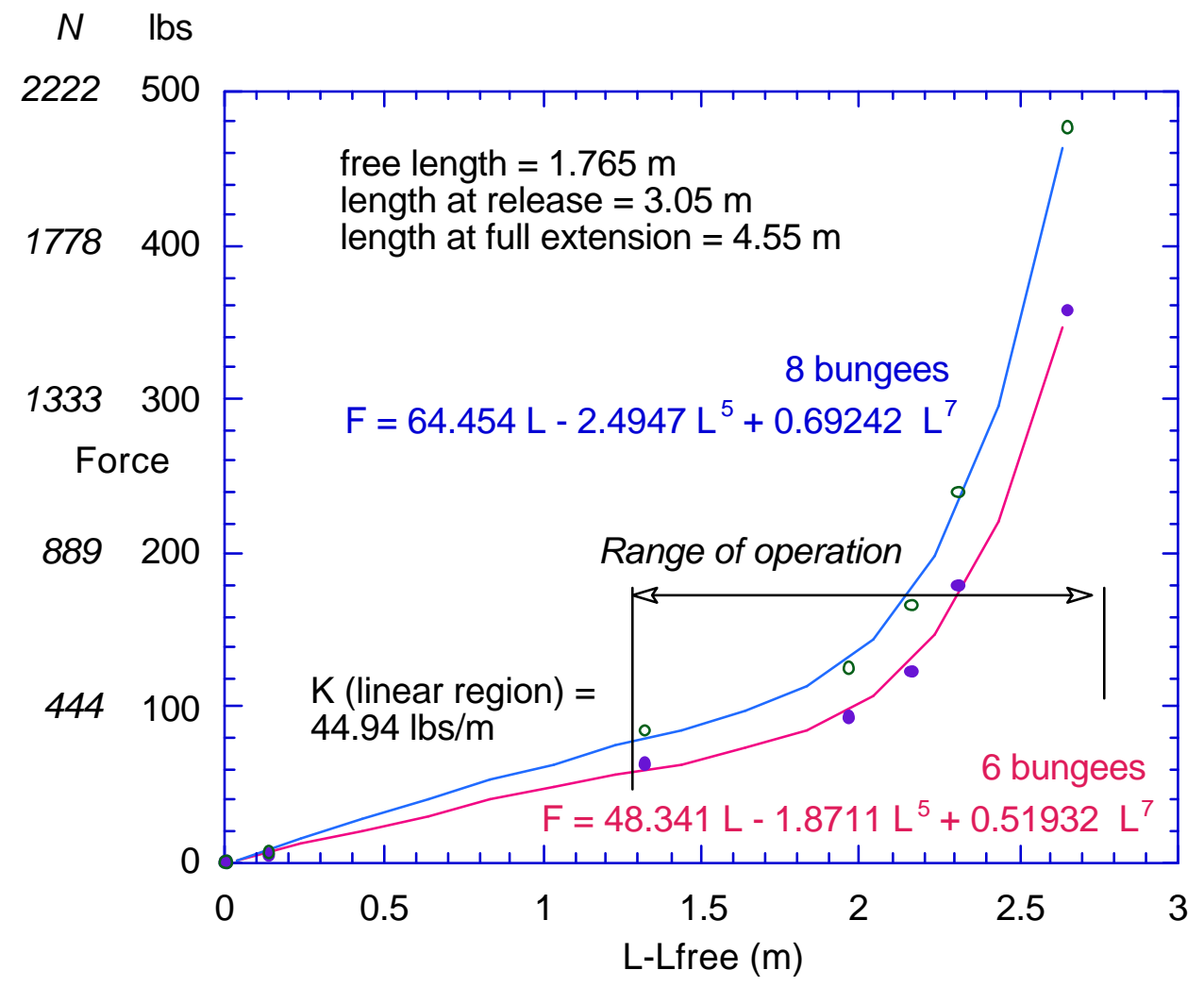

Figure 7. Force characteristics of bungee cords. 

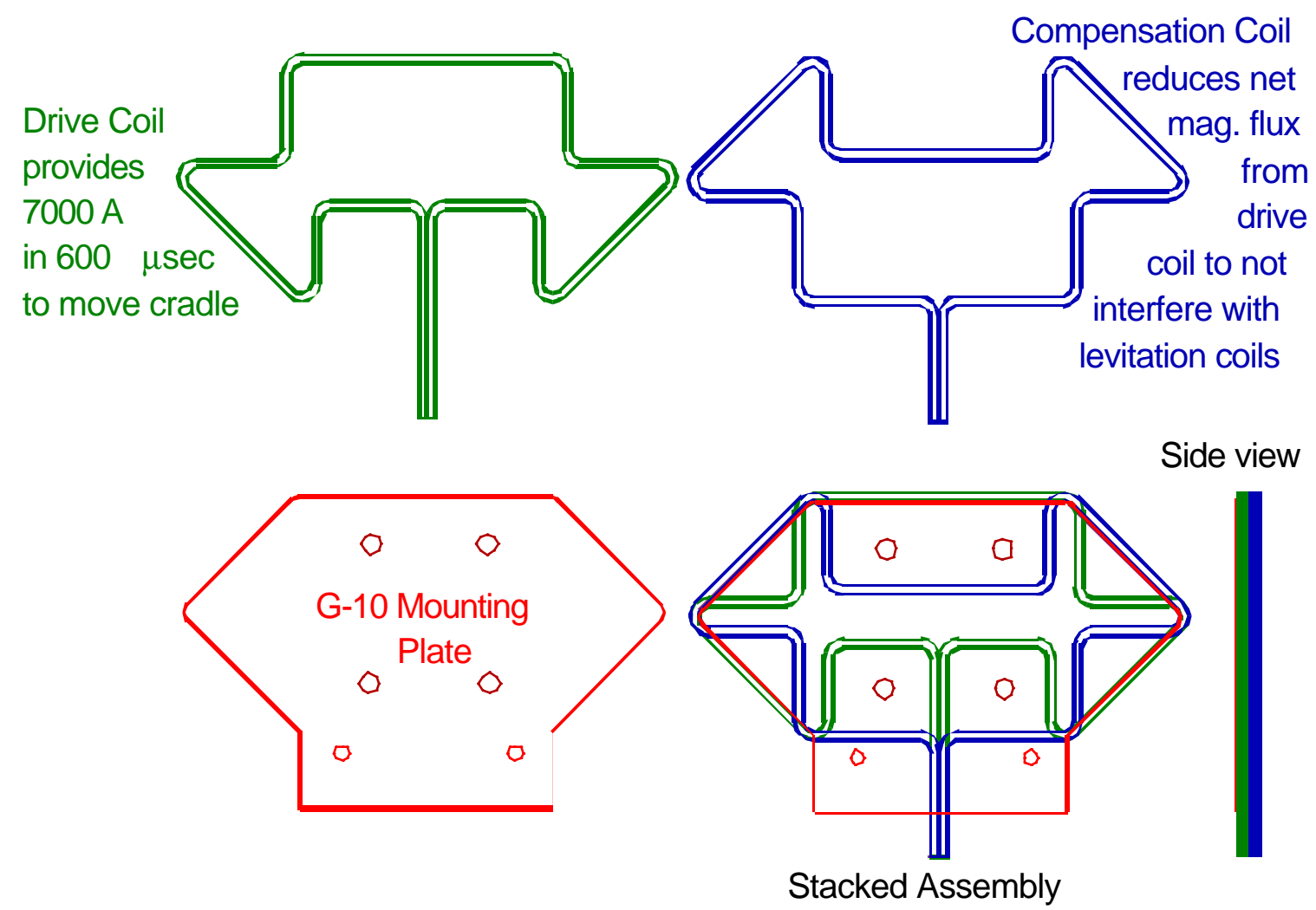

Figure 8. Drawing of the drive and compensation coils and how they overlay. Each drive and compensation coil is connected in series. 


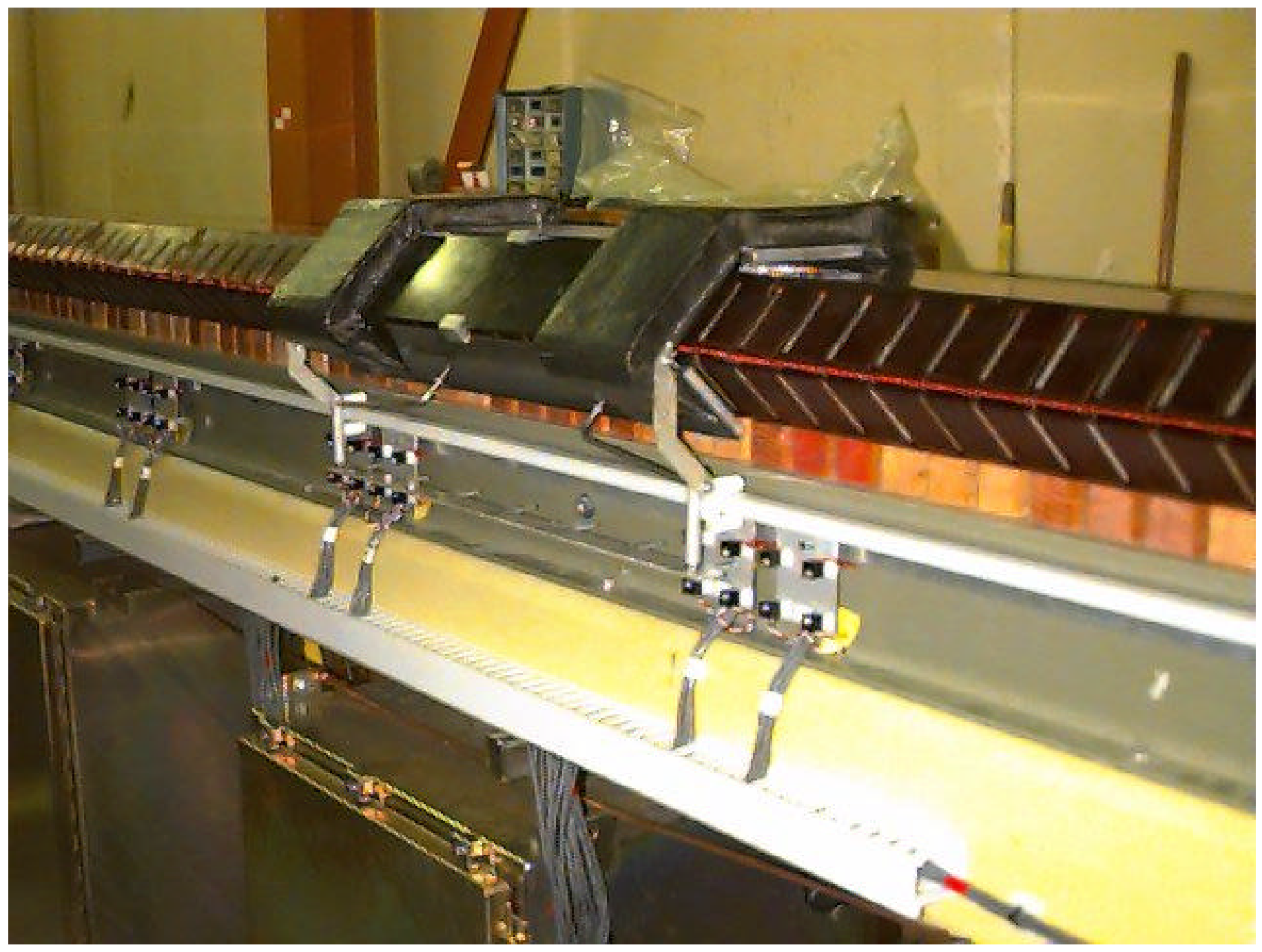

Figure 9. Close-up of the cradle, sensors, and comb that blocks the sensor signals in order to initiate the drive pulse as the cradle moves down the track. 


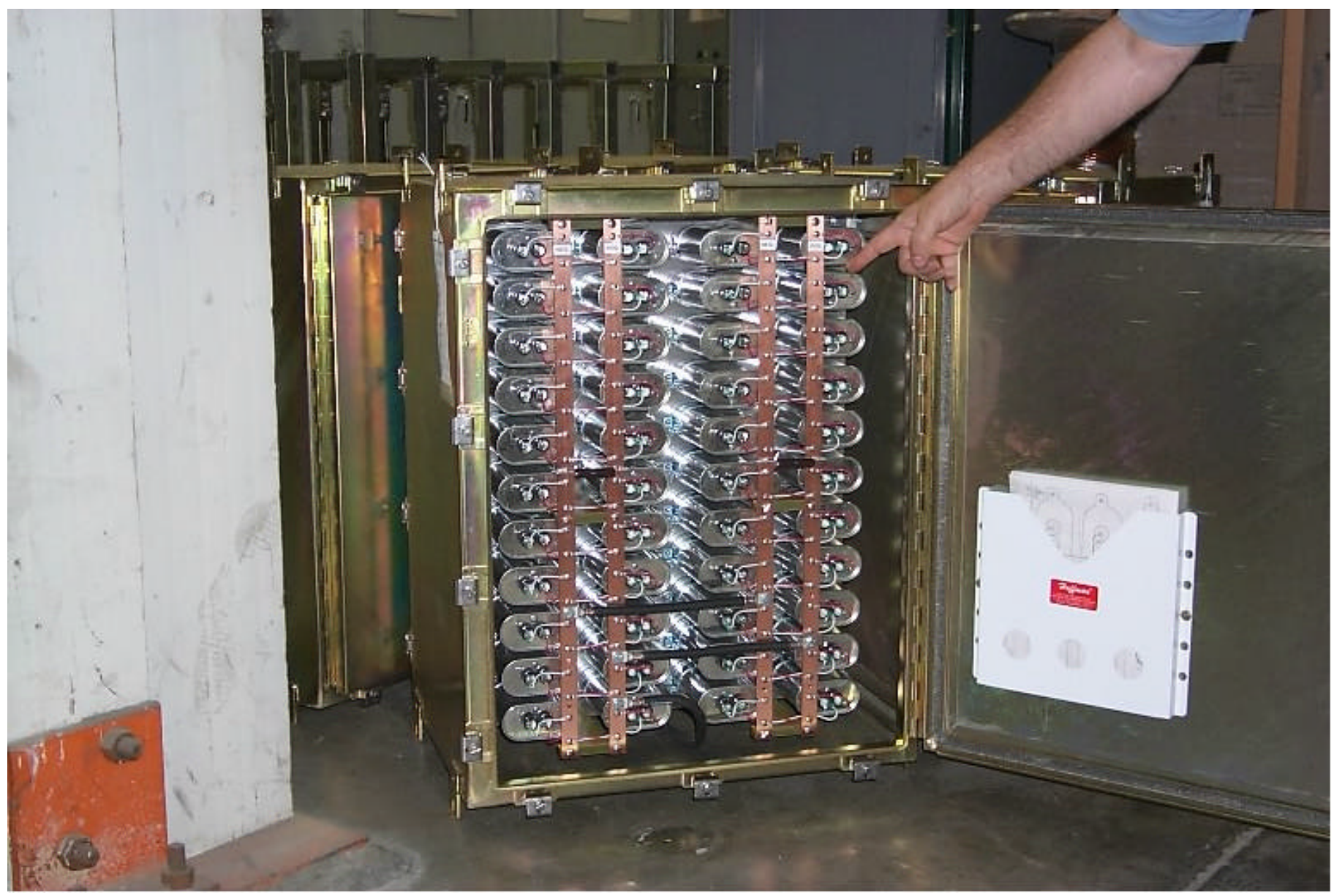

Figure 10. Resonant capacitor box (one of three). 


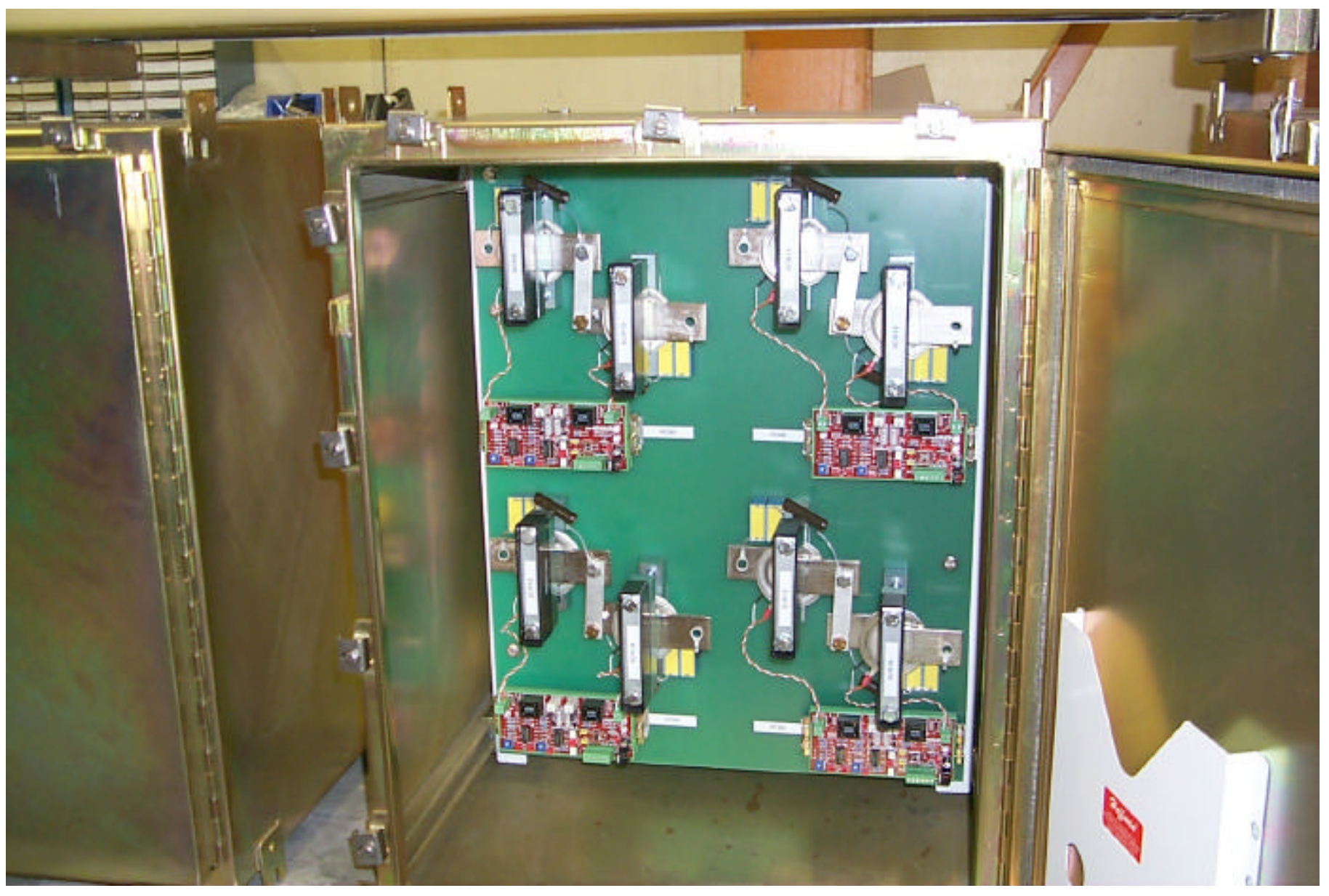

Figure 11. Thyristor box 


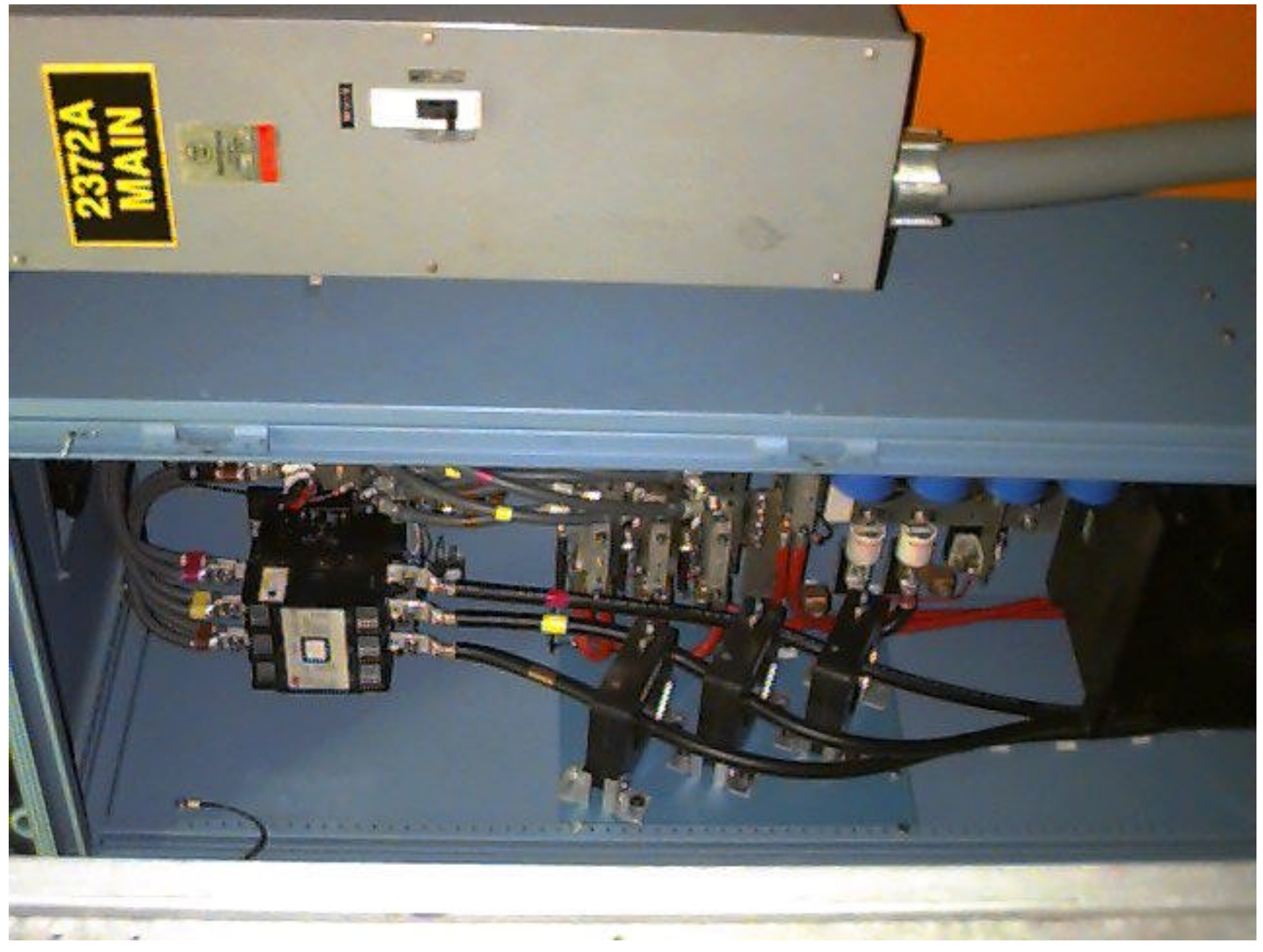

Figure 12. Power supply 


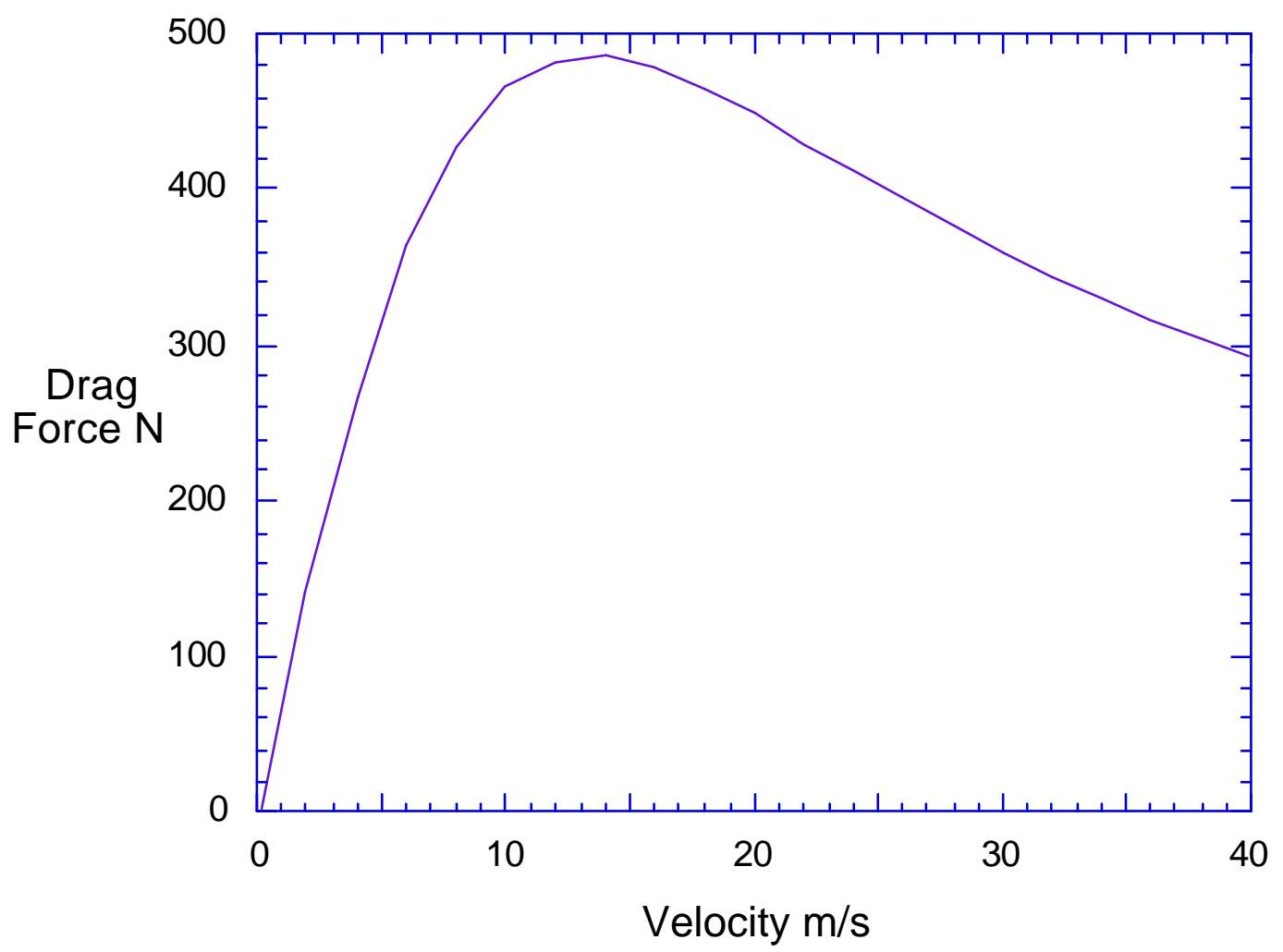

Figure 13. Dependence of drag force on cradle velocity. Peak drag force of $486 \mathrm{~N}$ is at $13.3 \mathrm{~m} / \mathrm{s}$. 


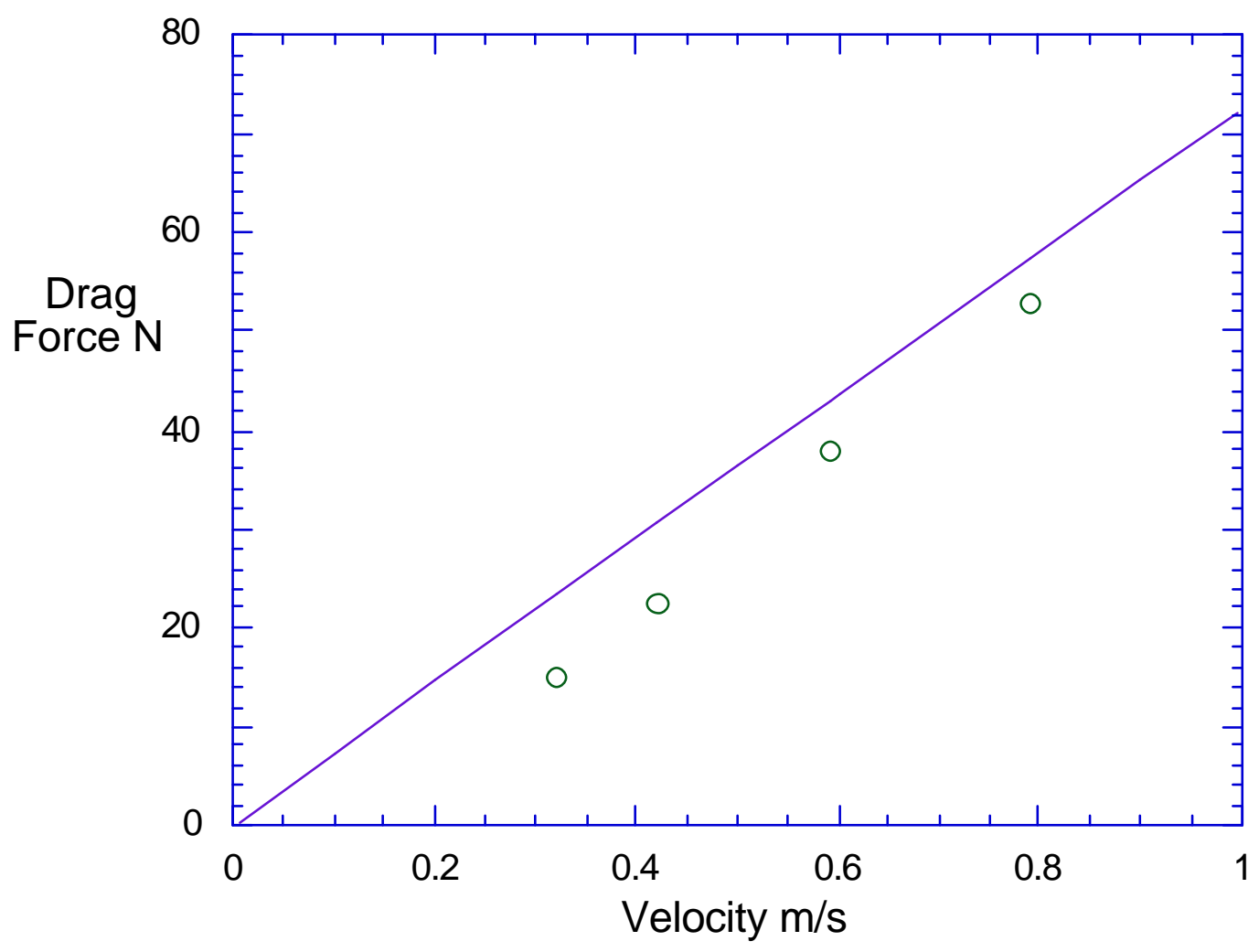

Figure 14. Dependence of drag force on cradle velocity at low velocities. Data points are taken from measurements at a walking speed. 


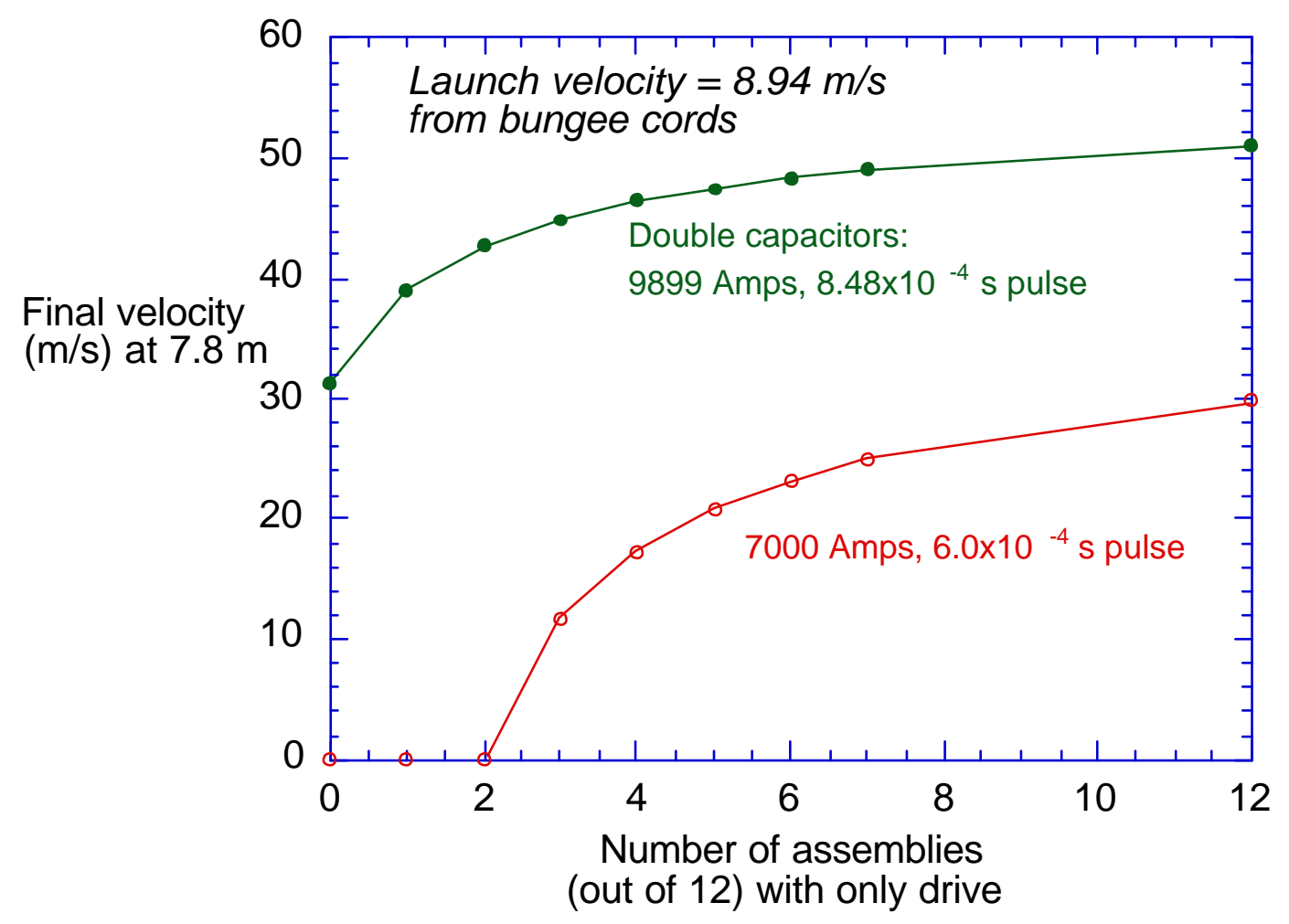

Figure 15. Final velocity at track end vs number of drive-only assemblies (out of 12) for using the existing resonant capacitors and for doubling the number of capacitors. 


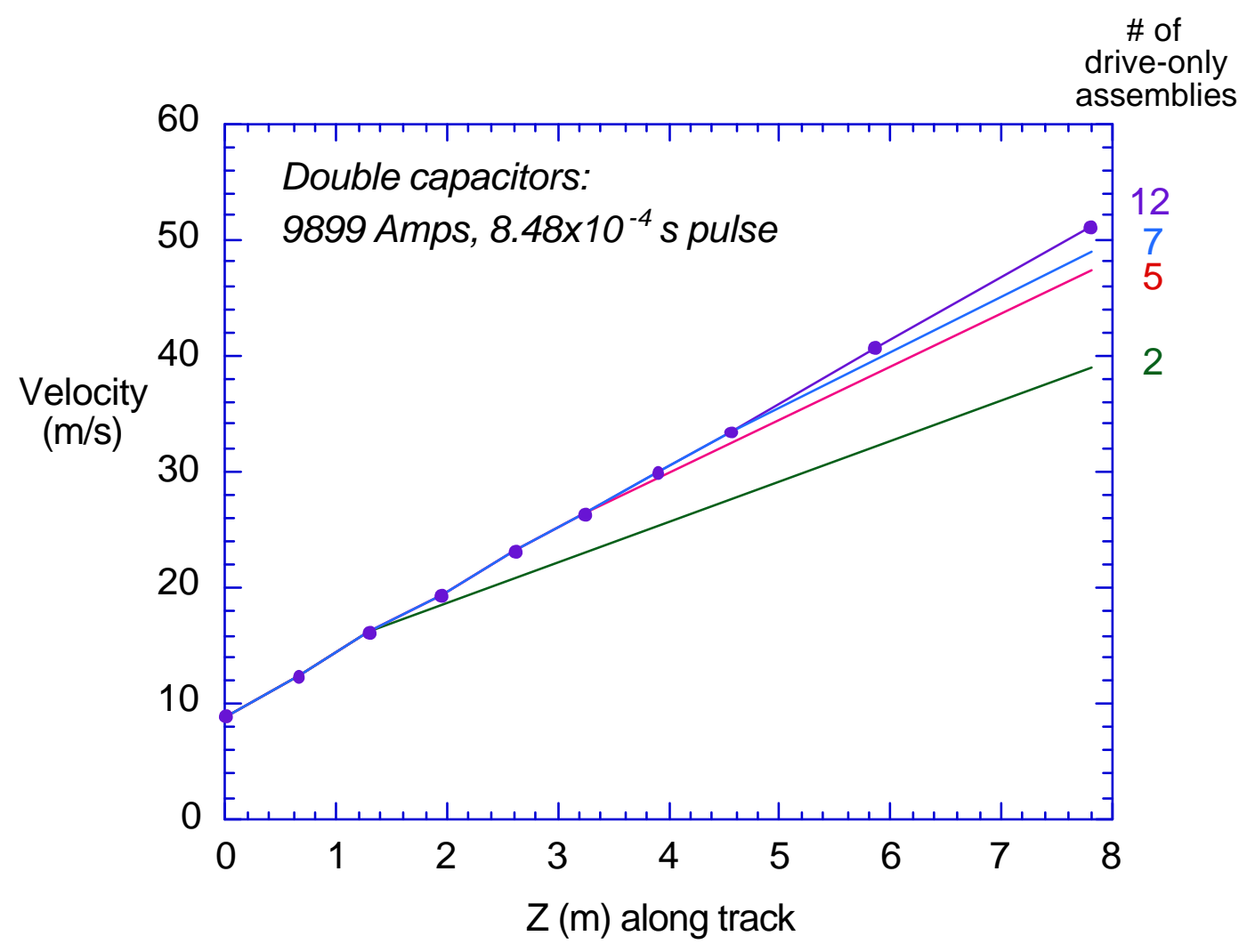

Figure 16. Velocity along the track with double the resonant capacitors for the four cases of 2, 5, 7, and 12 drive-only assemblies. Remaining assemblies out of 12 are levitation and drive. 